\title{
An unusual case of bilateral hydroureter: solved by a gynaecologist
}

\section{Nagendra Sardeshpande, Jainesh Doctor*}

Department of Obstetrics and Gynecology, Bombay Hospital and Medical Research Centre, Mumbai, Maharashtra, India

Received: 08 January 2018

Accepted: 03 February 2018

\section{*Correspondence:}

Dr. Jainesh Doctor,

E-mail: jainesh_doctor@yahoo.co.in

Copyright: (C) the author(s), publisher and licensee Medip Academy. This is an open-access article distributed under the terms of the Creative Commons Attribution Non-Commercial License, which permits unrestricted non-commercial use, distribution, and reproduction in any medium, provided the original work is properly cited.

\begin{abstract}
A 26-year unmarried girl presented with severe dysmenorrhoea and hesitancy of micturition during menses since, 2 years. She had history of regular menstruation. On IVP and ultrasound there was presence bilateral hydroureter and hydronephrosis. She had previous history of cystoscopy with bilateral ureteroscopy done for the same. Bilateral ureteric stenting for a period of 3 months was done 1 year earlier, however it failed to resolve the hydroureter. A MRI was done, which showed hydroureter with surrounding endometriotic nodule. Laparoscopy was done, and ureteral shaving was performed. Postoperative IVP showed normal ureteral and renal pelvic anatomy. Patient is presently on Dienogest and is asymptomatic.
\end{abstract}

Keywords: Bilateral hydroureter, Dysmenorrhoea and hesitancy, Hydronephrosis, IVP, MRI

\section{INTRODUCTION}

Endometriosis is defined as the presence of endometriallike tissue outside the uterus which results in chronic inflammatory reaction, scarring and anatomy-distorting adhesions in the pelvis. ${ }^{1}$ Although pelvis is the most commonly affected site by endometriosis, other organs/sites like lung, lymph node, scars and exceptionally kidney (urogenital system) is also known to be involved. ${ }^{2}$ In urogenital endometriosis one of the least involved structure is the ureter. Ureteral endometriosis, is a rare and silent disorder that can eventually lead to renal failure. Ureteral involvement can be limited to a single ureter, more often observed to be the left one, or both ureters with consequent urinary tract obstruction and hydroureteronephrosis.

Progressive ureteral obstruction can be insidious in onset and can ultimately lead to renal failure if a correct diagnosis is missed. It is often associated with nonspecific symptoms. Only a high index of suspicion and radiological support may help to obtain an early diagnosis.

\section{CASE REPORT}

A 26-year-old unmarried girl came with complains of severe dysmenorrhoea along with hesitancy of micturation since a period of 2 years. She had regular menstrual cycles. On examination she had minimal lower abdominal pain. She had previous ultrasound and IVP suggestive of hydroureter and hydronephrosis, for which cystoscopy with bilateral ureteroscopy had been done. She also gave history of undergoing bilateral ureteral stenting, a year back for relieving the hydroureter. The stent was removed after 3 months, however the hydroureter did not resolve. A fresh ultrasound was done which showed the persistence of the hydroureter. MRI of the abdomen and pelvis showed the hydroureter with surrounding hypointense nodule on $\mathrm{T} 2$-weighted images and hyperintense foci on T1-weighted images suggestive of endometriosis. Decision was taken to do diagnostic 
SOS operative laparoscopy for the same. Cystoscopy with bilateral ureteric stenting was done before starting with Laparoscopy. Intraoperative findings were suggestive of severe endometriosis with dense adhesions between bilateral adnexae and respective ovarian fossae and between rectum and lower uterine body. The ureters could not be localised.
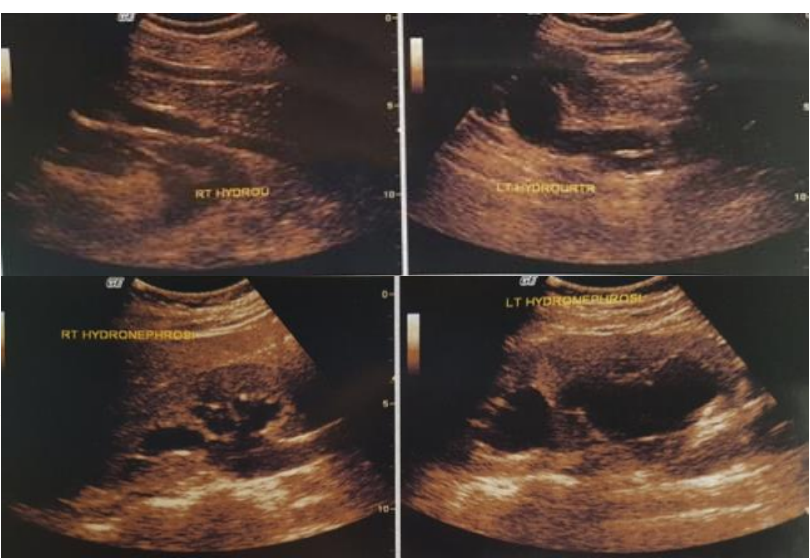

Figure 1: Preoperative USG-showing hydroureter and hydronephrosis.

The endometriotic nodules were excised and dissection was performed methodically in the posterior to anterior direction along the course of the ureter. The rectal adhesions to the uterine body were released and it was pushed down. Endometriotic nodule at the base of the uterosacral ligament was excised. The uterovesicle fold was cut anteriorly and the pubo-cervico-vesicle fascia was dissected down to expose the entry point of the right ureter into the bladder. By this process of ureteric shaving, the ureter along its entire pelvic course was made free of the endometriotic tissue. Similarly, adhesiolysis was performed between the left adnexa and the left ovarian fossa to reveal a normal left ovary and fallopian tube.

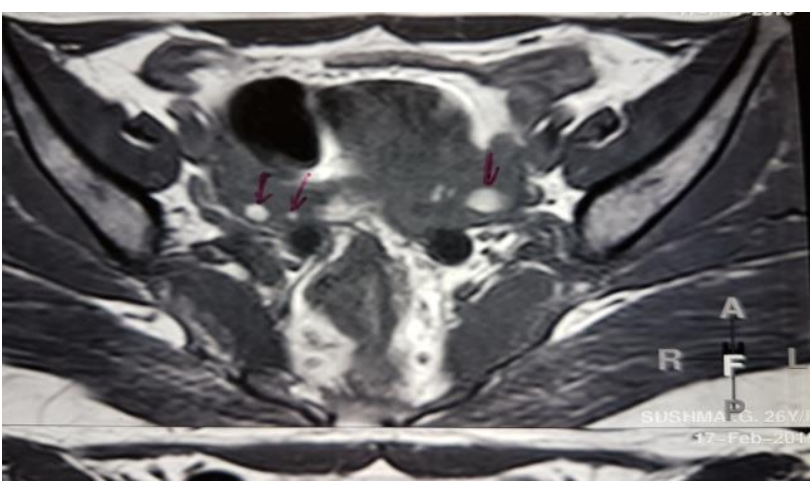

Figure 2: MRI (T1 weighted) images-showing bilateral ureteric dilatation with endometriotic nodule.

The left ureter was dilated and completely covered by endometriotic tissue, in a similar way as the right side. Ureteric shaving was performed in a similar fashion to the right side. The completeness of the procedure was checked and the entire pelvis was made completely free of the endometriotic tissue. Activated collagen was used as an adhesion barrier.

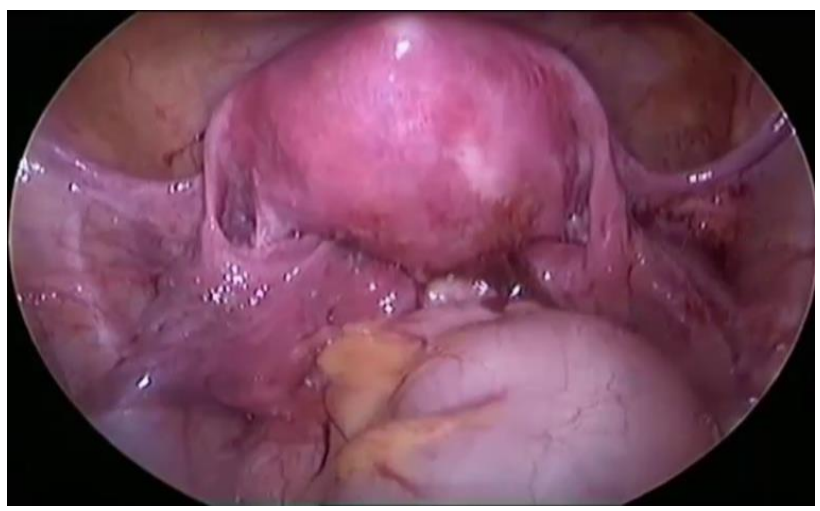

Figure 3: In-situ operative findings.

The patient had uneventful post operative period and was started on tablet Dienogest as a medical hormonal supression therapy for endometrisos, as the patient was not planning marriage and conception in near future. The ureteric stents were removed 3 months later. An Intravenous pyelogram was repeated 2 weeks after stent removal which showed normal ureteric and renal pelvic anatomy i.e. resolved hydroureter and hydronephrosis.
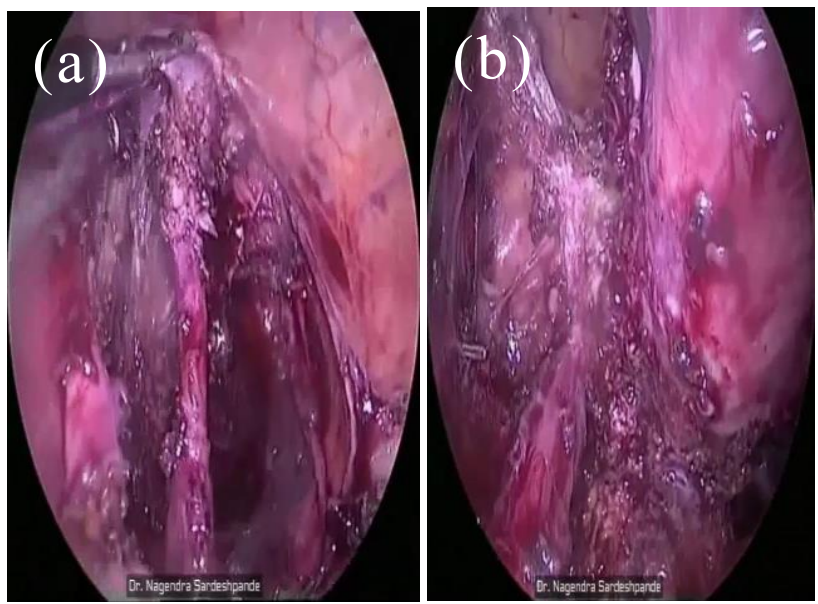

Figure 4: Post ureteric shaving (a) right ureter (b) left ureter.

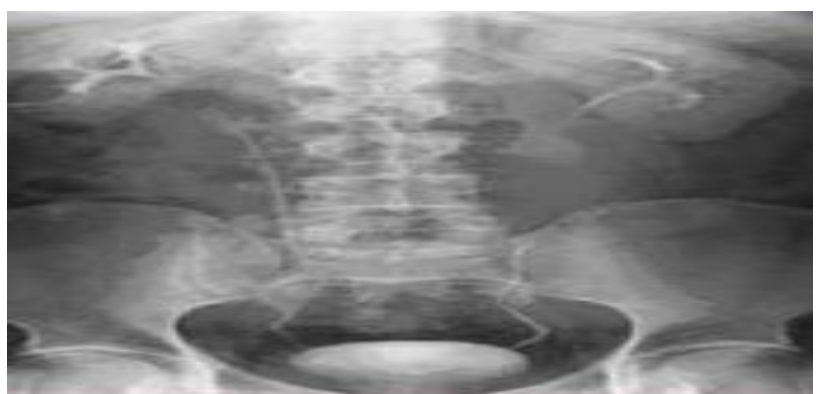

Figure 5: Postoperative IVP. 


\section{DISCUSSION}

Endometriosis is a clinical disorder characterized by ectopic functional endometrial tissue. It affects women in reproductive age group with increased prevalence in nulliparous and infertile women. Renal system involvement of endometriosis is very unusual i.e. of the entire menstruating women population, $15 \%$ are affected by endometriosis, of which $1.2 \%$ affect the urinary system with 40:5:1 affection of the bladder, ureter and kidney respectively. ${ }^{3}$ The ureter is usually involved below the level of pelvic brim. ${ }^{4}$ Its affliction is classified into intrinsic and extrinsic ureteral endometriosis (with a frequency ratio of 1:4). ${ }^{5}$ In most cases, the ureteral obstruction is due to the endometrial tissue surrounding the ureter (extrinsic ureteral endometriosis). The remaining cases have endometrial cells located within the ureter (intrinsic ureteral endometriosis). It is hypothesized as direct extension of endometrial cells outside the uterine wall favored by previous pelvic surgery. Supporting evidence to this fact is that it is preceded in most cases by hysterectomy with bilateral salpingo-oophorectomy (done for adenomyosis or pelvic endometriosis) done in women with complaints of pelvic pain. Lower third of the ureter has a strong predilection for involvement in extragenital endometriosis, as that part is most closely related to the uterus and cervix. Rectocervical and rectosigmoid junction lesions are noted with ureteral endometriosis, however coexisting bladder endometriosis is not known. ${ }^{6}$ In most of the cases the disease is clinically silent. ${ }^{7}$ In one third of the patients, it may be associated with non-specific symptoms such as dysmenorrhea, dyspareunia, dysuria, frequency, recurrent urinary tract infections, or lumbar pain. Chronic pelvic non-cyclic pain might also be a presenting symptom. Differential diagnosis include postoperative adhesions, acute appendicitis, pelvic varices, interstitial cystitis and irritable bowel syndrome. ${ }^{8,9}$ It is usually not associated with bladder disease. Diagnosis should be considered in women with renal symptoms of non-calculous obstruction, particularly in premenopausal women with history of polycystic ovary disease or severe menstrual related symptoms, although most commonly associated with silent renal obstruction. Imaging techniques play a limited role in diagnosis. The most commonly performed trans-abdominal ultrasonography may raise suspicion that could be confirmed by further investigations. Intravenous urography and spiral computed tomography localize the level, degree and laterality of ureteral involvement. However, urography is unable to identify the cause of an extrinsic obstruction. In the case of intrinsic endometriosis, urography may show a filling defect within the lumen of the ureter, but again this finding is not specific as it can be caused by stones or transitional cell cancer Magnetic resonance imaging (MRI) is sensitive and specific. ${ }^{10}$ It is accurate in differentiating between intrinsic and extrinsic forms. Lesions appear as hypointense nodule on T2-weighted images and hyperintense foci on T1-weighted images. It forms a useful preoperative tool. Ureteroscopy is very useful to diagnose intrinsic endometriosis. It gives a twodimensional endoluminal sonographic imaging of the ureter and can also demonstrate the periureteral anatomy. Laparoscopy allows direct localization of endometrial tissue around the ureter in cases of extrinsic endometriosis, while its role in patients with intrinsic endometriosis is limited. The main advantage is it identifies other foci of endoperitoneal endometriosis, especially in the region of the cul-de-sac. Laparoscopic adhesiolysis, ureteroureterostomy or ureteral reimplantation, although technically challenging, can be performed in the same sitting. ${ }^{11}$ Prognosis depends on the time of diagnosis. In case of an early diagnosis, an appropriate medical or surgical treatment may prevent renal function deterioration. Significant recurrence rate has been reported. Intrinsic ureteral endometriosis has been associated with upto $60 \%$ recurrence rate, however extrinsic endometriosis is successfully treated in $84 \%$ of the cases. Drugs induce temporary quiescence of active endometrial deep lesions and may be useful in selected circumstances. Progestins are the first-line medical treatment for temporary pain relief. Hormone therapy should be offered to patients of childbearing age who have the disease at an early stage and wish to have children. Ureteral lesions secondary to endometriosis can be treated by cystoscopy and JJ stent. However, in most cases of severely infiltrating disease, surgery is the final solution, particularly in case of intrinsic ureteral obstruction. $^{12}$ Surgical treatment may consist of ureteroneocystostomy, laparoscopic ureterolysis, with later ureteral resection and end-to-end anastomosis. Systematic ureteric stenting prior to surgical dissection of the pelvic wall is recommended. Ureteric reimplantation onto a psoas hitch bladder must be performed when the endometrial lesions are extensive and partly resected or invade the ureteric wall. The frequency of associated lesions (urinary, gynecological and gastrointestinal) justifies a multidisciplinary surgical approach. ${ }^{13}$

Funding: No funding sources

Conflict of interest: None declared

Ethical approval: Not required

\section{REFERENCES}

1. Bulletti C, Coccia M, Battistoni S, Borini A. Endometriosis and infertility. J Assisted Reproduct Genetic. 2010;27(8):441-7.

2. Rousselot F, Liard-Meillon ME. Renal endometriosis. Report of one case. Prog Urol 1996;6:936-9.

3. Stillwell T, Kramer S, Lee R. Endometriosis of ureter. Urol. 1986;28(2):81-5.

4. Yohannes P. Ureteral endometriosis. J Urol. 2003;170:20-5.

5. Pérez M, Aguilera Bazán A, Alonso Dorrego JM, Hernández A, de Francisco MG, Martín Hernández $\mathrm{M}$, et al. Urinary tract endometriosis: clinical, diagnostic, and therapeutic aspects. Urol. 2009;73:47-51. 
6. Abrão MS, Podgaec S, Dias JA, Averbach M, Silva LF, Marino de Carvalho F. Endometriosis lesions that compromise the rectum deeper than the inner muscularis layer have more than $40 \%$ of the circumference of the rectum affected by the disease. J Minim Invasive Gynecol. 2008;15:280-5.

7. Seracchioli R, Mabrouk M, Manuzzi L, Guerrini M, Villa G, Montanari G, et al. Importance of retroperitoneal ureteric evaluation in cases of deep infiltrating endometriosis. J Minim Invasive Gynecol. 2008;15:435-9.

8. Vercellini $\mathrm{P}$, Somigliana E, Viganò $\mathrm{P}$, Abbiati A, Barbara G, Fedele L. Chronic pelvic pain in women: etiology, pathogenesis and diagnostic approach. Gynecol Endocrinol 2009;25:149-58.

9. Giri SK, Long RM, Barry D, Flood HD, Moran KT. Ureteral endometriosis and ovarian mucinous cystadenoma presenting with acute pyonephrosis. Ir J Med Sci. 2005;174:67-70.

10. Ghezzi F, Cromi A, Bergamini V, Bolis P. Management of ureteral endometriosis: areas of controversy. Curr Opin Obstet Gynecol. 2007;19:319-24.

11. Generao SE, Keene KD, Das S. Endoscopic diagnosis and management of ureteral endometriosis. J Endourol. 2005;19:1177-9.

12. Horn LC, Do Minh M, Stilzenburg JU. Intrinsic form of ureteral endometeriosis causing ureteral obstruction and partial loss of kidney function. Urol Int. 2004;73:181-4.

13. Marcelli F, Collinet P, Vinatier D, Robert Y, Triboulet JP, Biserte J, et al. Ureteric and bladder involvement of deep pelvic endometriosis. Value of multidisciplinary surgical management. Prog Urol. 2006;16:588-93.

Cite this article as: Sardeshpande N, Doctor J. An unusual case of bilateral hydroureter: solved by a gynaecologist. Int J Reprod Contracept Obstet Gynecol 2018;7:1273-6. 